\title{
Value of a bipolar modified inferior lead in detection of inferior myocardial ischaemia
}

\author{
CHRISTIAN M JESPERSEN, VERNER RASMUSSEN \\ From the Medical Department, Division of Cardiology and the Holter Laboratory, Municipal Hospital, \\ Copenhagen, Denmark
}

SUMMARY Only bipolar leads are normally available for ambulatory monitoring. Bipolar precordial leads are reliable for detecting left coronary artery insufficiency, but may not detect changes caused by right coronary artery insufficiency. The magnitude and polarity of ST segment changes in a bipolar modified inferior lead and in CM5 were compared with those in standard electrocardiographic leads in 10 consecutive patients with acute myocardial infarction (eight inferior and two anteroseptal). The polarity of the ST segment in the modified orthogonal y lead was the same as that in aVF in all eight patients with inferior myocardial infarction and in six the size of the ST segment shift was identical in the two leads as well. In two patients the ST segment shift was larger in the modified orthogonal $y$ lead than in aVF. In one of the two patients with anteroseptal myocardial infarction the polarity of the ST segment shift was the same in the modified orthogonal y lead and aVF. In the other patient it was slightly different. The CM5 lead did not reliably detect inferior myocardial ischaemia.

A modified orthogonal y lead is suitable for the detection of inferior myocardial ischaemia.

Several non-invasive techniques are available for the diagnosis of coronary artery disease. Ambulatory ST segment monitoring, however, is the only one that gives information on myocardial ischaemia during normal daily activity. The precordial leads and in particular CM5, which is the one most commonly used, reliably detect ischaemia in the anterior wall of the heart but may fail to detect right coronary artery insufficiency. ${ }^{1}$ This may be because the recording sites are restricted to the anterior aspect of the thorax, and a lead representing the vertical axis of the body, such as y lead that is used in spatial electrocardiography, might be better for recording the activity of structures lying towards the back of the thorax including the inferior wall of the heart.

We have tested this hypothesis by comparing the recordings obtained from a modified orthogonal y lead with those of the standard electrocardiographic leads and CM5.

Requests for reprints to Dr Christian M Jespersen, Medical Department C, Bispebjerg Hospital, Bispebjerg Bakke, DK 2400 Copenhagen N, Denmark.

Accepted for publication 3 June 1988

\section{Patients and methods}

We studied 10 consecutive patients with acute myocardial infarction. Nine patients had recent infarction, seven in the inferior wall and two in the anteroseptal wall. We studied one during premonitory ischaemia, which subsequently became inferior infarction. We identified the site of infarction from the characteristics of abnormal $Q$ and $T$ waves in the standard electrocardiogram, and the diagnosis was confirmed by increases in serum enzymes. We excluded patients with arrhythmia, conduction disturbances, or electrocardiographic indications of ventricular hypertrophy or strain or both. None of the patients was on digoxin or other antiarrhythmic drugs and none complained of chest pain during the recording period.

We recorded a standard 12 lead electrocardiogram before Holter monitoring (table). This electrocardiogram was used as a reference standard for the subsequent Holter recording.

In all patients we obtained a 30 minute Holter recording with a two channel Holter recorder (Spacelabs, model 90201). One channel recorded the modified orthogonal y lead. Both electrodes of this lead were placed just to the left of the spinal column. 
Table Site of myocardial infarction and changes in the 12 lead standard electrocardiogram before Holter monitoring in the 10 patients

\begin{tabular}{|c|c|c|c|c|}
\hline \multirow[b]{2}{*}{ Patient No } & \multirow[b]{2}{*}{ Site of myocardial infarction } & \multicolumn{3}{|l|}{ ECG changes in: } \\
\hline & & Inferior wall & Septum & Anterior wall \\
\hline $\begin{array}{r}1 \\
2 \\
3 \\
4 \\
5 \\
6 \\
7 \\
8 \\
9 \\
10\end{array}$ & $\begin{array}{l}\text { Inferior, } Q \text { wave } \\
\text { Inferior, } Q \text { wave } \\
\text { Inferior, } Q \text { wave } \\
\text { Inferior, } Q \text { wave } \\
\text { Inferior, } Q \text { wave } \\
\text { Inferior, non- } Q \text { wave } \\
\text { Inferior, } Q \text { wave } \\
\text { Inferior lateral ischaemia } \\
\text { Septum, } Q \text { wave } \\
\text { Septum, non- } Q \text { wave }\end{array}$ & $\begin{array}{l}\text { Q wave, ST elevation } \\
\text { Q wave, ST elevation } \\
\text { Q wave, ST elevation } \\
\text { Q wave, ST elevation } \\
\text { Q wave, negative T wave } \\
\text { Negative T wave } \\
\text { Q wave, ST elevation } \\
\text { ST depression } \\
\text { ST depression } \\
\text { - }\end{array}$ & $\begin{array}{l}\bar{Z}^{\star} \\
\text { ST depression } \\
\overline{-} \\
\bar{Z} \\
\overline{\bar{Q}} \text { wave, ST elevation } \\
\text { Negative T wave }\end{array}$ & $\begin{array}{l}\text { 二 } \\
\text { ST depressiom } \\
\text { ST depression } \\
\text { ST depression- } \\
\text { ST elevation } \\
\text { ST depressiona } \\
=\end{array}$ \\
\hline
\end{tabular}

The negative electrode was positioned on the superior angle of the scapula and the positive one above the iliac crest. The other channel recorded lead CM5 with the electrodes in conventional positions.

The Holter recordings were produced as a two channel real time printout $(25 \mathrm{~mm} / \mathrm{s})$ from a computer for Holter analysis (Spacelabs Arrhythmiamaster 90101). The tapes were analysed by visual inspection. ST segment changes were measured $80 \mathrm{~ms}$ after the J point; we used a line drawn between two consecutive PR segments as the baseline.

\section{Results}

Figure 1 shows the ST segment level of the modified orthogonal y lead, aVF, and CM5. In patients who had inferior myocardial infarction shown by the standard electrocardiogram the ST segment of the modified orthogonal y lead resembled that of the aVF lead. Four patients with ST elevation in aVF (cases 1, 2,3 , and 7) showed similar changes in the recording from the modified orthogonal y lead. In two (cases 1 and 3) the degree of ST elevation in recording from the modified orthogonal y lead was identical with that in the aVF recording, and in two the elevation was higher than in aVF $(+0.17$ and $+0.1 \mathrm{mV}$ and +0.25 and $+0.15 \mathrm{mV}$ in cases 2 and 7 respectively). When there were no changes in the aVF recording there was none in the modified orthogonal y lead either (cases 4,5 , and 6). The aVF and y lead recordings also corresponded in patient 8 in whom recordings were obtained during an episode of posterolateral ischaemia that eventually progressed into an inferior infarction. In patient 8 the degree of ST segment depression was equal in $\mathrm{aVF}$ and the modified orthogonal y lead. In two patients with anteroseptal infarction (cases 9 and 10) the resemblance between aVF and the modified orthogonal y lead recording was less pronounced. Patient 9 showed ST segment depression of -0.13 and $-0.20 \mathrm{mV}$ in $\mathrm{aVF}$ and the modified orthogonal y recordings respectively. In patient 10 there was slight ST elevation in the modified orthogonal y lead but no changes in aVF. $\overrightarrow{ }$

In patients with inferior myocardial infarction the polarity of CM5 was the same as that in the aVF leacf in only four patients (cases 1, 2, 5, and 7) (fig 1b).
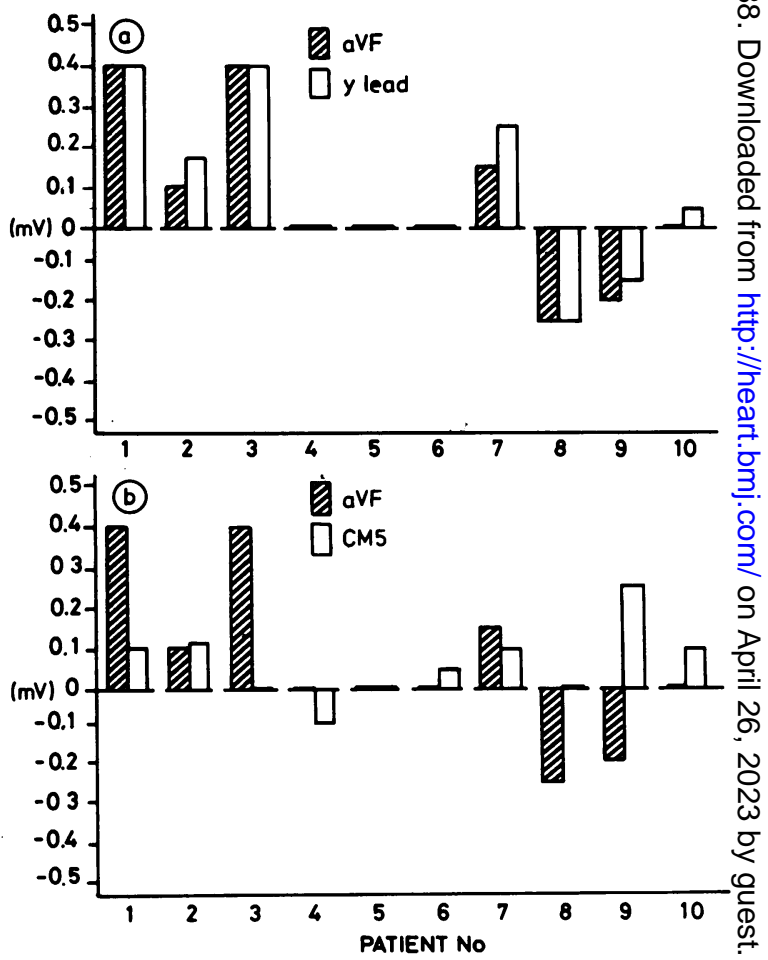

Fig 1 (a) Polarity and magnitude of $S T$ segment changes in aVF and modified orthogonal y leads in patients with acute myocardial ischaemia. (b) Polarity and magnitude of $S T$ segment changes in $a V F$ and CMS leads in patients with acute myocardial ischaemia. 


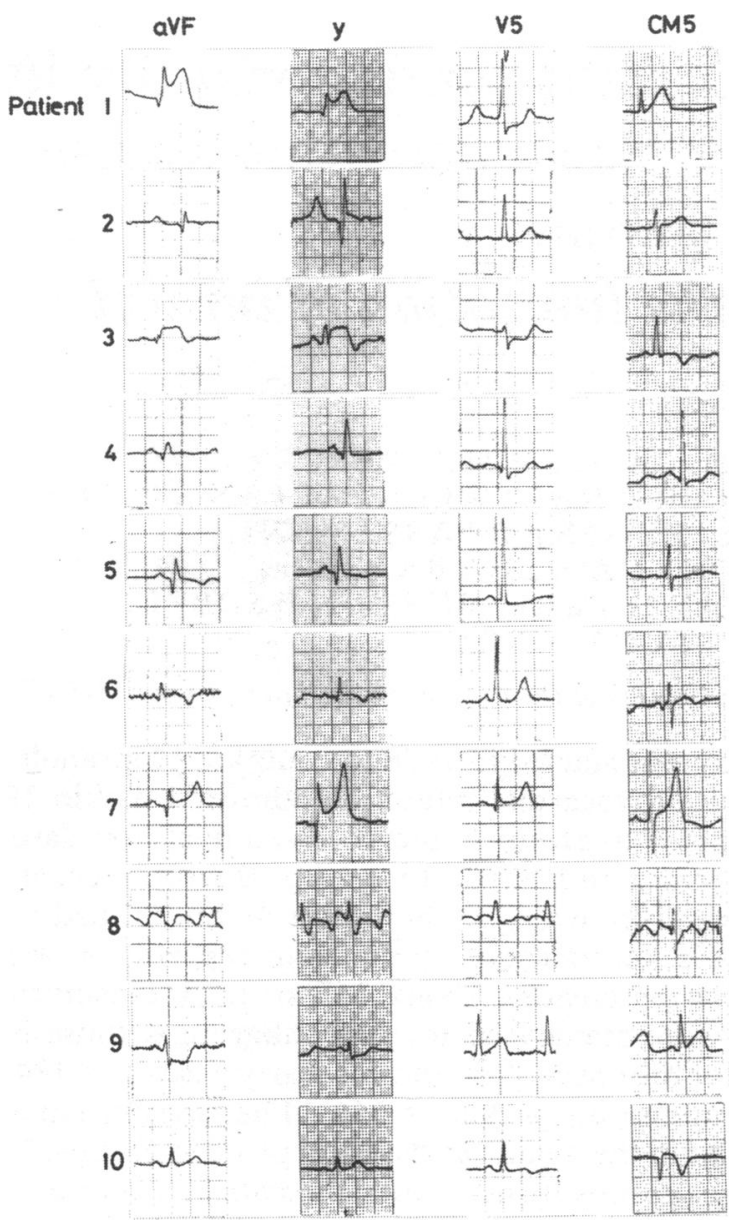

Fig 2 Electrocardiographic changes in aVF, modified orthogonal $y, V 5$, and CMS leads in 10 patients with acute myocardial infarction.

\section{Discussion}

Multiple lead electrocardiography is more sensitive than single lead systems for the detection of coronary insufficiency. In the standard electrocardiogram two bipolar (II, III) and one unipolar lead (aVF) are used to show inferior myocardial ischaemia. For Holter monitoring only two bipolar leads are usually available. CM5 is usually chosen as one of these because it is a sensitive detector of anterior myocardial ischaemia. $^{2}$ In patients with right coronary insufficiency, however, ST segment changes may be missed if only precordial leads are used. ${ }^{12}$

Cristal et al proposed a bipolar precordial "aVFlike" lead for the detection of electrocardiographic changes in the inferior wall. ${ }^{3}$ They placed the negative pole under the outer third of the left clavicle and the positive pole at the left anterior axillary line in the 9-10th intercostal space. They found a good agreement in about two thirds of their patients between the modified lead and aVF. But precordial leads mainly record electrical forces generated by the anterior wall of the heart rather than those that originate in more distant cardiac structures such as the inferior wall. If an "aVF-like" electrocardiogram is recorded from a lead from the left precordium it does not prove that this lead is recording the same activity in the inferior wall as shown by the true standard aVF lead. An "aVF-like" electrocardiogram is more likely to resemble activity in the precordial leads recorded from the same region (V4V6), which in the absence of ventricular hypertrophy or strain or both may resemble the aVF. ${ }^{4}$ The opinion that leads recorded from the precordial area are unreliable in detecting ischaemia in the inferior wall was supported by the study of Quyyumi et al. ${ }^{2}$ Using an "inferior-like" precordial lead, they found no changes in ST segment in patients with isolated right coronary insufficiency, unless similar changes were present in the CM5 lead.

We compared a modified inferior bipolar recording with a simultaneously recorded standard 12 lead electrocardiogram. By placing the electrodes away from the precordial area in a cranial-caudal position we obtained a bipolar lead resembling the unipolar aVF lead (fig 2). We found that in patients with ST elevation caused by a recent inferior infarction the changes in ST segment in this modified orthogonal y lead were the same as those seen in aVF. The findings in those two leads were also similar in those with ST depression caused by myocardial ischaemia or representing reciprocal changes during anterior infarction. Because the ST segment changes in CM5 did not sufficiently resemble the changes in aVF, CM5 should not be used to detect inferior ischaemia.

For Holter monitoring we recommend the use of a modified orthogonal y lead to record ischaemia in the inferior wall and a CM5 lead for the detection of ischaemia in the anterior wall.

\section{References}

1 Quyyumi AA, Crake T, Mockus LJ, Wright CA, Rickards AF, Fox KM. Value of the bipolar lead CM5 in electrocardiography. $\mathrm{Br}$ Heart $J$ 1986;56: $372-6$.

2 Quyyumi A, Crake T, Wright C, Mockus L, Fox K. The role of ambulatory ST segment monitoring in the diagnosis of coronary artery disease: comparison with exercise testing and thallium scintigraphy. Eur Heart $J$ 1987;8:124-9.

3 Cristal N, Gueron M, Hoffman R. 'V1-like' and 'aVFlike' leads for continuous electrocardiographic monitoring. Br Heart J 1972;34:696-8.

4 Goldman MJ. Normal electrocardiographic complexes. In: Principles of clinical electrocardiography. 7th ed. Los Altos, California: Lange Medical Publications, 1970:54-5. 